\title{
Interdisciplinary in Costume Design the Application of Compound Talents
}

\author{
Zheng Jingjing, Ruan Jinhua, Hu Shouzhong \\ Fashion Design and Engineering, Shanghai University of Engineering Science, Shanghai, China
}

Email address:

1512719402@qq.com (Zheng Jingjing)

To cite this article:

Zheng Jingjing, Ruan Jinhua, Hu Shouzhong. Interdisciplinary in Costume Design the Application of Compound Talents. Education Journal. Vol. 5, No. 4, 2015, pp. 71-74. doi: 10.11648/j.edu.20160504.15

Received: October 27, 2015; Accepted: November 13, 2015; Published: July 6, 2016

\begin{abstract}
The comprehensive quality of the clothing market for dress design talents, ability demand is higher and higher, and the single costume design talents knowledge framework, which requires the domestic institutions of higher learning of clothing talent costume design professional learning, not only to consolidate the knowledge, also need to learn and clothing cross discipline, due to too many related disciplines, need to interdisciplinary screening. This article through the literature search, interdisciplinary extraction phase factor, then the research method. Main factors analysis method of Spss software is used to determine the main and the clothing design disciplines, which in turn to fashion design talent training mode, can hope to talent cultivation in the clothing design a certain reference value.
\end{abstract}

Keywords: Clothing Design, Talent Training, Inter-disciplinary Talent, Interdisciplinary

\section{Introduction}

"Made in China" has always been like a double-edged sword affects the development of Chinese apparel industry, relying on the "made in China" China's garment industry has made great breakthroughs, costume design talents also arises at the historic moment, have sprung up to grow up. However, as "China to create" slogan is put forward, the expansion of the clothing market, demand for fashion design talent already not just stay in the mastery of professional knowledge. Modern clothing market prefers costume design talents, and domestic colleges and universities developed "achievement" often don't meet the demanding of the market [1].

In this paper, we study is applying costume design related disciplines to develop inter-disciplinary talent? In this paper, through investigation, and SPSS software to analyze the factors, find out main clothing design related disciplines, and analyzes its application in the design of Shanghai engineering and technology university institute of clothing, then to the costume design talents training mode, can hope to talent cultivation in the clothing design a certain reference value.

\section{Interdisciplinarity and Interdisciplinary Talents}

\subsection{Interdisciplinarity}

\subsubsection{The Meaning of Interdisciplinarity}

Interdisciplinarity is blend of academic thought. There are various ways of interdisciplinary; Cross span, increasing. The level of the crosses the deepening. Interdisciplinarity is the interaction between the academic disciplines, and cross formation of the theoretical system, a cross subject; Many cross subject constitutes the interdisciplinary sciences.

\subsubsection{The Aims of Interdisciplinarity}

A: Interdisciplinary frontier interdisciplinary sciences lead to many

For example: particle cosmology, biophysical chemistry, biology, mathematics, science, environmental science, space, system science, natural science ethics of sociology and social nature, and so on. So far, the number of interdisciplinary has reached more than 000 more than 2, many of which are crossed the frontier of science.

B: For a comprehensive solution to major problems facing humanity. A country's development strategy, the general policy, general policy formulation, the major decisions, such 
as political, military and economy are most in need of comprehensive knowledge, can say, almost systemic knowledge across all subject areas. Population, food, energy, ecology, environment, health problems, such as only on any single subject or a big science cannot solve effectively, and only through the discipline overlapping between the most likely solution.

\subsection{Interdisciplinary Talents}

\subsubsection{The Meaning of Interdisciplinary Talents}

Interdisciplinary talents should be in each aspect has certain ability, in a certain specific ways to excel, to the inter-disciplinary talent should not only has outstanding experience in professional skills, also has high relevant skills. For dress design talents, learning costume design and other interdisciplinary promotes the development of its comprehensive, simply grasp the fashion design professional knowledge, has far cannot satisfy the market demand for dress design talents. Clothing market need is compound talents [2].

Master professional skills, and hands-on inter-disciplinary talent high salary every year. Shanghai labor and social security bureau yesterday issued a full-time position salary guide price show that the composite talent shortage of wage growth of $15 \%$ last year, demand for interdisciplinary talents in the visible market increases year by year, inter-disciplinary talent's market favor.

\subsubsection{Fashion Design Ways for the Cultivation of the Talents}

1. Increase the contents of the costume design discipline overlapping: clothing market marketing, psychology, management, law (intellectual property) computer, advertising, aesthetics.

2. To strengthen the construction of practice, training of theory combining with practice, attach importance to students' practical operation ability.

3. Structures at home and abroad to study and communication platform: the interaction of colleges and universities at home and abroad, reference and learning.

4. To strengthen the construction of double, interdisciplinary faculty: internal and external mentor.

5. To optimize the design of the clothing student's course: eliminate and costume design talent training is not high, the correlation increases relatively important.

\subsection{Importance in Costume Design Compound Talents Cultivation of Interdisciplinarity Analysis}

1) In terms of clothing design innovation industry, clothing design innovation industry has the characteristics of strong permeability and high value-added, higher requirements for the discipline of crossover and integration. By clothing industry grew out of the creative product design innovation embodies more intelligent, personalized, artistic color obvious phenomenon of culture and technology and blend with each other. So the clothing design innovation of industrial structure of human resources requirements specification is higher, the clothing design innovation industry requires special skills it is needless to say, the artistic talents and interdisciplinary knowledge under the background of a number of skills, can in respect of the organic combination of science and art has attainments is a costume design talents [3].

2) from the perspective of clothing market, due to the development of the clothing market have multiple disciplines, traditional professional costume designer already can't satisfy the needs of clothing market, in order to better and faster development, it needs more compound talents with interdisciplinary background. And one of the ways for the cultivation of the talents is to cross education between disciplines.

\section{The Survey of Content Related to Fashion Design Course Cross}

\subsection{With Costume Design Interdisciplinary Extraction}

There are two main ways that extract: literature summary and the method of expert interview. Thus summed up: clothing market marketing, consumer psychology, management, advertising, law (intellectual property), computer, aesthetics and so on seven.

\subsection{With the Clothing Design of Interdisciplinary Research Design}

This research mainly adopts questionnaire survey as the main method of collect study materials, along with questionnaires, supplemented by interview method, in view of the data analysis in question is used to verify and understanding. The results of questionnaire as shown in table 1.

Table 1. Questionnaire Recovery Situation.

\begin{tabular}{ll}
\hline & questionnaire \\
\hline The amount of questionnaire & 300 \\
The amount of received questionnaire & 260 \\
The amount of effective questionnaire & 200 \\
effective rate & $86.6 \%$ \\
\hline
\end{tabular}

By gender points, including the boy 175 , accounting for $58.3 \%$; girls, 125 , accounting for $41.7 \%$. By profession points, including 136 students, 45.3\%; Teacher, 97 (32.3\%), shown in figure 1 , figure 2 as follows.

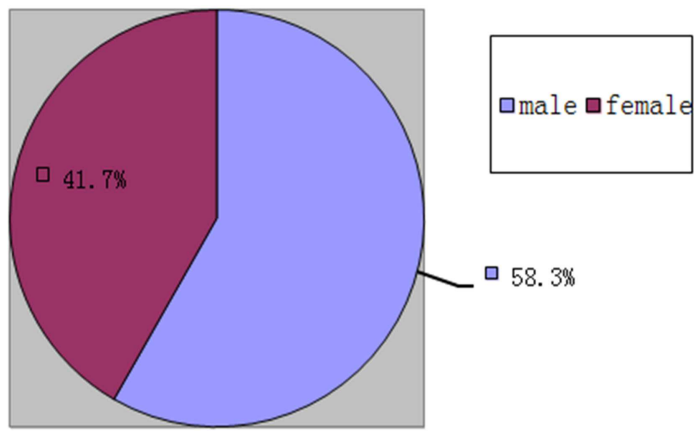

Figure 1. Questionnaire recovery ratio. 


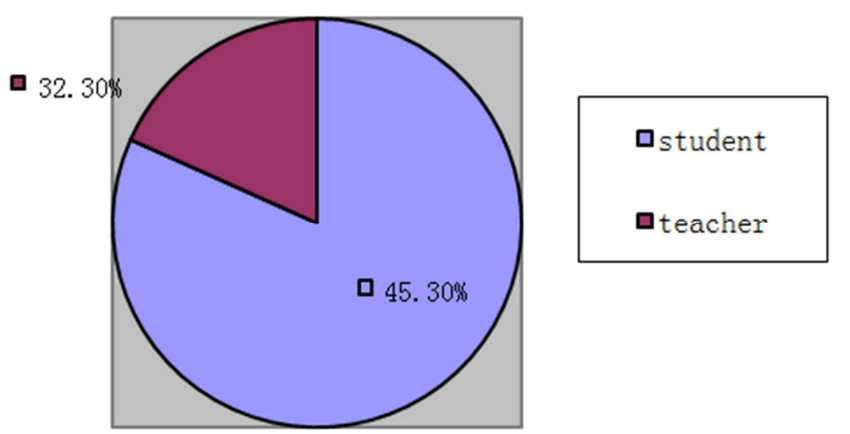

Figure 2. Questionnaire recycling of the pie chart shown pie proportion of different careers.

Costume design related discipline with the letter $\mathrm{L}, \mathrm{M}, \mathrm{N}$, $\mathrm{O}, \mathrm{P}, \mathrm{Q}, \mathrm{R}$, for each related discipline frequency of 1 to 5 points. Can be seen from the table below seven related disciplines scores on 2 to 5 minutes, and appear in the ratio of 1 is relatively small. The total score on the right side of each related subjects to develop for its value multiplied its corresponding to the sum of the proportion. Thus, consumer psychology, computer and aesthetics attract more concern and attention.

\section{Data Statistical Processing and Chart Production}

\subsection{Correlation Test}

The purpose of this test is to validate the gender, professional design related disciplines to clothing to choose whether or not have a significant impact, but also to verify the correlation between clothing design related discipline. Through the inspection, the garment design related discipline correlation between the choices of small, interaction between almost can be ignored. And gender, professional for fashion design have little impact on the choice of relevant subject, can be ignored.

\subsection{Scale Reliability Validity Analysis}

The reliability test of the crowns Bach reliability coefficient method is adopted, Cronbach's alpha coefficient between 0 and 1 , if the alpha 0.9 or higher, argues that scale has a high reliability; If acuities were alpha $0.8<0.8$, argues that the reliability is acceptable; If acuities were alpha $0.7<$ 0.7 , explain certain problems scale design. This study has a scale, analysis of garment design related disciplines, a total of seven measuring item. In this paper, I use Cronbach's alpha reliability estimation method to estimate the reliability of questionnaire.

$$
\alpha=\frac{k}{k-1}\left(1-\frac{\sum s_{i}^{2}}{s^{2}}\right)
$$

Among them, the alpha for reliability coefficient, $\mathrm{k}$ as title number, the variances of the questionnaire for each topic, $\mathrm{s}^{2}$ said the variance of test scores.

Table 2. Items in Total Statistics.

\begin{tabular}{lllll}
\hline & $\begin{array}{l}\text { The average scale } \\
\text { has been deleted }\end{array}$ & $\begin{array}{l}\text { A deleted } \\
\text { scale } \\
\text { variance }\end{array}$ & $\begin{array}{l}\text { Correction } \\
\text { of a total } \\
\text { correlation }\end{array}$ & $\begin{array}{l}\text { A deleted } \\
\text { Cronbach's } \\
\text { Alpha }\end{array}$ \\
\hline $\mathrm{L}$ & 23.65 & 11.510 & .691 & .811 \\
$\mathrm{M}$ & 23.70 & 12.130 & .580 & .827 \\
$\mathrm{~N}$ & 23.91 & 11.083 & .716 & .806 \\
$\mathrm{O}$ & 24.00 & 11.273 & .585 & .828 \\
$\mathrm{P}$ & 23.74 & 12.656 & .566 & .830 \\
$\mathrm{Q}$ & 23.87 & 11.755 & .598 & .825 \\
$\mathrm{R}$ & 23.83 & 12.059 & .505 & .839 \\
\hline
\end{tabular}

Table 3. Reliability Statistics.

\begin{tabular}{ll}
\hline Cronbach's Alpha & subject \\
\hline .845 & 7 \\
\hline
\end{tabular}

\subsection{Costume Design Related Disciplines Factor Analysis}

Table 4. KMO and Bartlett's test.

\begin{tabular}{lll}
\hline \multicolumn{2}{l}{ Take out the enough Kaiser-Meyer-O1 kin metrics } & $\mathbf{. 7 0 2}$ \\
\hline \multirow{3}{*}{ Bartlett Sphericity test } & The approximate chi-square & 63.738 \\
& df & 21 \\
& Sig. & .000 \\
\hline
\end{tabular}

The table 4 shows that the Kaiser-Meyer-O1kin has a value of 0.648 is close to 1 , so the factor is stable, can proceed the following factor analysis.

Table 5. Clothing related disciplines the interpretation of the total variance.

\begin{tabular}{llllll}
\hline \multirow{2}{*}{ Ingredients } & \multicolumn{2}{l}{ The initial eigenvalue } & & \multicolumn{2}{c}{ Extraction of sum of squares loaded } \\
\cline { 2 - 6 } & sum & variance \% & cumulative \% & sum & variance \% \\
\hline 1 & 5.079 & 72.571 & 72.571 & 5.079 & 72.571 \\
2 & .995 & 14.220 & 66.791 & & 72.571 \\
3 & .728 & 10.394 & 77.185 & & \\
4 & .676 & 9.660 & 86.845 & & \\
5 & .534 & 7.630 & 94.475 & & \\
6 & .240 & 3.429 & 100.000 & & \\
7 & .147 & 2.096 & & \\
\hline
\end{tabular}


From clothing related subjects gravel figure, there are 1-7 respective factors abscissa, and the $y$ coordinate for the eigenvalues. Factor 2 as the turning point, and the characteristic value of the factor 2 is less than 1 , so should factor 1 is put forward. Again the table 5 shows that the initial eigenvalue factor 1 is more than one, according to the extraction of sum of squares in the last two columns of load and rotate the sum of squares load, the factor 1 can explain the original seven variables are $72.571 \%$ of the total variance.

By component matrix can be known, $\mathrm{L}, \mathrm{N}$ load on factor 1 is higher, more than $0.8, \mathrm{O}, \mathrm{Q}$ in high load on factor 1 , between $0.70 .8 \mathrm{M}, \mathrm{P}, \mathrm{R}$ low load on factor 1 , between 0.6 to 0.7 . Interleaving factor 1 named discipline.

\section{Conclusion}

This article is mainly about the clothing design talent training courses on the basis of reasonable structure, which is from the perspective of interdisciplinarity learning costume design talents for need of related disciplines, and through factor analysis, determine which subject should be the first to enter the clothing design talent training course modules, more targeted to cultivate interdisciplinary talents market need.

But, in this paper, the preliminary design to clothing discipline overlapping content choice by relying on nothing more than to find a lot of literature, thus will cause the loss of part of the content of interdisciplinarity. Questionnaire survey efficiency is not high at the same time, resulting in a decrease of the amount of data, which affect the results of the calculation of deviation. In addition to the concrete implementation plan of the costume design talents cultivation also need to continue to complement. Hope that this article studies the content of the talent cultivation in the clothing design to a certain reference value.

\section{Acknowledgement}

This study was funded by Science Technology Commission of Shanghai Municipality, the funded project No. 11510501600 and Municipal Education Commission of Shanghai, the funded project No. 13ZS128.

\section{References}

[1] Li Zi Yang. Creative industry type personnel training mode of interdisciplinarity and its importance [J], art theories, 2012 (3), $42-43$

[2] Qin Jia. Creative industry and art talents training [J], China university of science and technology, 2012 (8).

[3] Li Ke Jing, Tian He Wei. Costume design professional instructors studio study $[\mathrm{J}]$ compound talents cultivation system, the textile and clothing education, 2012 (4).

[4] Wei Shan (2013). Research on Combination Mode of College Art Education and Computer Art.

[5] Xu Le. Independent colleges applied costume design professional personnel training mode research [D]. Jiangxi, jiangxi normal university, 2011

[6] Dang Yi, Zhang Zhi. Costume design professional talent training is an effective means [D]. Beijing: Beijing union university teachers college, 2010

[7] Yu Yi Qing, Ling Ni. The international perspective of China's high-level creative design thinking and exploration on talent training pattern, the theory of modern decoration [J]. Zhejiang university of technology, 2011. 